\title{
MULTIDIMENSIONAL DIAGNOSIS OF OCCUPATIONAL PRESSURE PERCEPTION FOR THE MEDICAL STAFF OF AN INTENSIVE CARE UNIT (ICU)
}

\author{
Elena-Luminița BOULEANU, Adrian Tudor BRATE \\ "Lucian Blaga" University of Sibiu, Romania \\ elena.bouleanu@ulbsibiu.ro, adrian.brate@ulbsibiu.ro
}

\begin{abstract}
Intensive Care Units (ICU) medical staff is frequently subject of great amount of psychological and physical occupational pressure. There are three main sources of pressure: professional responsability for the medical act, organizational requirements and interpersonal/intrapersonal relationships.

Materials and method: The paper presents a study on the multidimensional diagnosis of occupational pressure/stress perception of the medical staff of an ICU $(N=34)$. The romanian form of Pressure Management Indicator (PMI) [1][2][3][7] was applied to all participants. The instrument is designed for multidimensional evaluation of occupational stress. The objective was to identify specific indicators of occupational pressure and formulate predictions regarding the different variables.

Results and conclusions: Data analysis showed, for example, that Influence and Control (as personality factors/individual differences) are good predictors for the resilience level in the studied ICU medical staff. We can conclude that individual differences regarding personality factors are the main variables that significantely influence the occupational stress coping for ICU medical staff. The PMI-RO diagnosed profile, resulted for the ICU medical staff showed many differences comparing with general population, including sources of pressure, coping strategies, personality factors, organisational satisfaction and self evaluation of performance. Further implications of the study and intervention strategies for medical personnel in ICU are discussed.
\end{abstract}

\section{Keywords: Pressure Management, ICU medical staff}

\section{Introduction}

Intensive Care Units (ICU) medical staff is frequently subject of great amount of psychological and physical occupational pressure, due to stressful situations for patients, relatives and other professionals. "A growing body of evidence suggests that burnout among ICU nurses and ICU physicians is a remarkable result of the demanding and continuously high stress work environment. It has been suggested that ICU professionals could be emotionally affected by end-of-life issues, ethical decision making, observing the continuous suffering of patients, disproportionate care or medical futility, miscommunication, and demanding relatives of the patients. Moreover, many patients in the ICU lack decision making capacity; therefore, the healthcare professionals depend on communication with relatives for decision making, which can complicate the communication process. In addition, the ICU work environment has become increasingly technical, which requires extended skills in advanced life sustaining medical therapies" [6, p.2]. The intense stress environment that ICU professionals practice in, are highly demanding on cognitive level (loss of attention concentration, errors in decision making, irritability or hostility, low selfconfidence), on physical level (sleeping disturbances, headaches, low back pain) 
and on emotional level (emotional burnout, compassion fatigue, guilt or helplessness).

The purpose of this study was to offer a multidimensional diagnosis of the perception of occupational pressures at individual and group/department level for Romanian medical staff in an ICU, for improving professional life and proposing specific intervention/ management strategies.

\section{Methodology}

\subsection{Participants}

As participants for this research, we included 34 health care professionals from an ICU (doctors and nurses), with the following demographic characteristics: 11 males (32.4\%), 23 females (67.6\%), average age in organization 15.47 years, with a standard deviation of 8.87; type of occupation / position: 21 nurses (61.8\%) and 13 physicians $(38.2 \%), 25$ of the participants have university diploma.

\subsection{Instruments}

The participants have completed the romanian translated and adapted version of the Pressure Management Indicator (PMIRO [1,2,3,7], that includes a biographical questionnaire, eight scales and 24 subscales, that measure the sources and effects of socio-professional pressures, coping strategies and individual differences. After filling out the questionnaire, scoring it and transforming the data in percentile scores, we obtain a profile/graph for the studied ICU staff, that can be compared to other profiles or to the adapted cultural standard. The graph that figure the profile of the related indicators and scales of occupational stress for the particpants of this study, will be presented in the results section.

\section{Results}

The data were processed through a specialized statistical program. In the first stage of data processing, descriptive statistical values have been obtained, then, by examining significant relationships between the measured variables, correlation analysis was processed. For examining the role of possible significant predictive variables, regression analysis was used.

\subsection{Descriptive analysis}

We have selected some significant descriptive data. Regarding the motivation for performing overtime work hours of the medical staff, Table 1 shows the frequencies for each type of motivation. It is also important that all 34 participants declare they work overtime every week (an average of 49.65 hours/week). The tipe of motivation shoes that an important amount of overtime working hours is due to complete the work and the fact that it is expected from them. This can be interpreted as task overload, lack of efficiency and/or a high level of obeisance to authority.

Table 1 The motivation for performing overtime work (hours)

\begin{tabular}{|c|l|c|c|}
\hline \multicolumn{2}{|c|}{ Type of motivation } & Frequency & Percent \\
\hline \multirow{4}{*}{ Valid } & Personal/ own choice & 10 & 29,4 \\
\cline { 2 - 4 } & It is expected from me & 12 & 35,3 \\
\cline { 2 - 4 } & To complete the work started & 12 & 35,3 \\
\cline { 2 - 4 } & Total & 34 & $\mathbf{1 0 0 , 0}$ \\
\hline
\end{tabular}

Self-evaluation of performance is shown in Figure 1, with an average of 85.74 and a standard deviation of 11.66: the self- perceived evaluation of occupational performance indicates a trend of positive relative high level of self-assessment. 


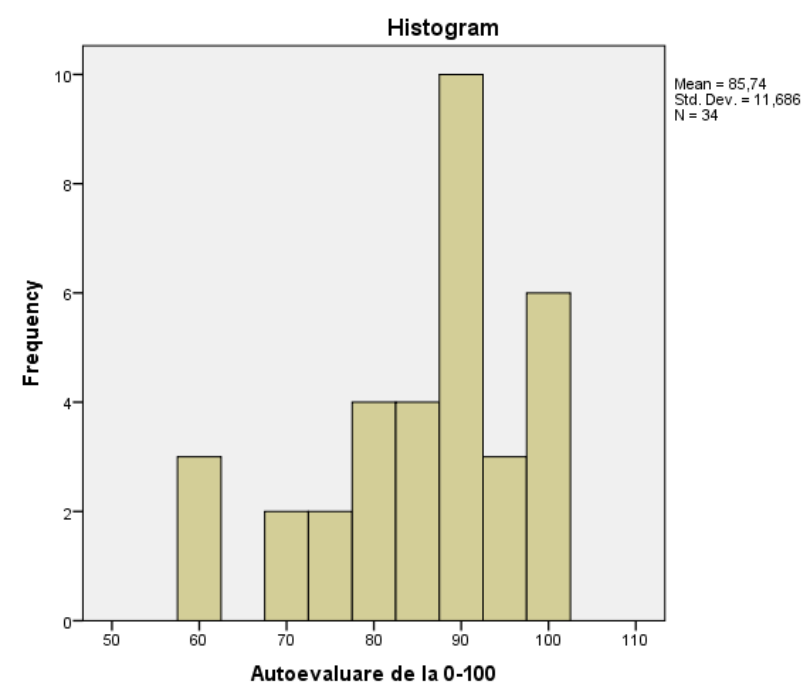

Figure 1: Self-evaluation of occupational performance

\subsection{The profile of pressure management indicator for the ICU medical staff}

After calculating the scales and subscales scores of the PMI questionnaire and transforming them into percentiles we obtained the resulting profile shown in Figure 2. The following aspects, we are particularly interested in the study:

- The ICU staff perceive relatively high levels of sources of pressure regarding: recognition, daily hassless, workload, organisational climate and managerial role, and relatively low pressure came from home/work balance and personal responsability;

- As coping strategies, they use more the life/work balance (this explains the low score on this aspect as pressure source showing in the previous paragraph) and the problem focus strategies, and they tend to use less the social support;
- Analysing the role of personality and individual differences, the profile shows lower levels of perceived personal influence and control than the occupational standards, and above mean scores on drive $A$ and impatience.

- Regarding the perceived effects of occupational stress/pressures we can observe that the participants declare low levels of organisational satisfaction and confidence, medium level of job satisfaction, lower levels of physical well-being and energy level, but surprisingly high levels of resilience, organisational commitement, state of mind and organisational security.

This findings will be discused more in the conclusion section of the paper. 
ANNEX 1

THE EVALUATION (IN CENTILES) OF INDICATORS AND SCALES OF PRESSURE MANAGEMENT INDICATOR

PARTICIPANTS N $=34 \mathrm{ICU}$ medical staff

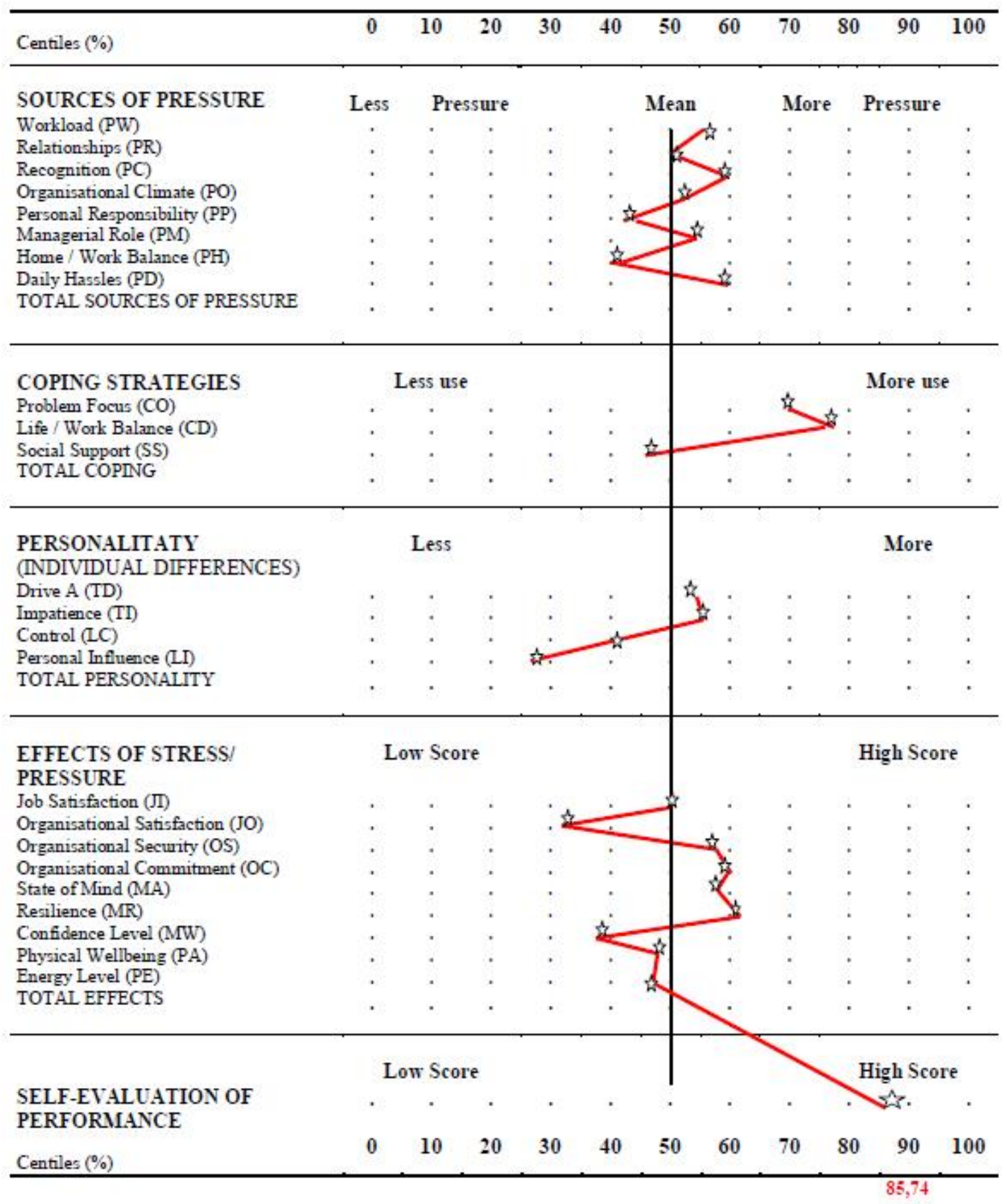

Figure 2: The profile of pressure management indicator for the ICU medical staff

3.3. Correlational analysis and predictors of the effects of occupational pressures

We present a selection of interesting significant correlations between the measured variables:
- Gender with energy level: $r=-.48$ $(\mathrm{p}<.01)$, social support: $r=.44(\mathrm{p}<.01)$, physical well-being: $r=-.37 \quad(\mathrm{p}<.05)$ women tend to experience higher levels of energy loss and physical symptoms 
than men, but tend to use more often social support as a coping strategy;

- The number of real overtime workhours/week the medical staff really do with organisational commitment: $r=.34$ $(\mathrm{p}<.05)$, personal influence: $r=.36$ $(\mathrm{p}<.05)$, organisational security: $r=-.38$ $(\mathrm{p}<.05)$ and type $A$ drive: $r=-.44(\mathrm{p}<.01)$ - the more extra work hours they report, the more they have a feeling of commitment and personal influence, but experience a decrease of the level of organisational security and less type A drive;

- The amount of months/professional experience in the ICU with pressure from relationships: $r=-.43 \quad(\mathrm{p}<.01)$, organisational climate: $r=-.35(\mathrm{p}<.05)$, personal responsibility: $r=-.44(\mathrm{p}<.01)$ - a longer professional experience is due with a lower level of pressure;

- Self-evaluation (0-100 scale) with the coping strategy life-work balance: $r=-$ $.35(\mathrm{p}<.05)$ - participants who score high on self-evaluation on professional performance tend to score low on lifework balance coping strategy. We infer that the high scores on self-evaluation for our studied group have some causes that were not measured with this instrument;

- Job satisfaction with energy level: $r=-$ $.33(\mathrm{p}<.05)$, drive $A: r=-.38(\mathrm{p}<.05)$, and control: $r=-.35(\mathrm{p}<.05)$;

- Organisational satisfaction with drive $A: r=-.41(\mathrm{p}<.05)$;

- Organisational security with physical well-being: $r=.34(\mathrm{p}<.05)$, and daily hassles: $r=-.35(\mathrm{p}<.05)$;
- Organisational commitment with personal influence: $r=.40(\mathrm{p}<.05)$, and problem focus: $r=.55(\mathrm{p}<.01)$;

- State of mind with physical wellbeing: $r=.67 \quad(\mathrm{p}<.01)$, energy level: $r=.70$ $(\mathrm{p}<.01)$, drive A: $\quad r=.38 \quad(\mathrm{p}<.05)$, impatience: $r=-.37(\mathrm{p}<.05)$, and control: $r=.46(\mathrm{p}<.01)$;

- Resilience with confidence level: $r=.34$ $(\mathrm{p}<.05)$, and control: $r=.51(\mathrm{p}<.01)$;

- Physical symptoms with life/work balance: $r=-.46(\mathrm{p}<.01)$ and confidence level: $r=.48(\mathrm{p}<.01)$;

- Energy level with recognition: $r=-.35$ $(\mathrm{p}<.05)$ and organisational climate: $r=$ $.35(\mathrm{p}<.05)$.

To identify and test predictor patterns, linear regression analysis, for explanatory purposes was applied. In the following tables $(2,3,4,5)$ we have identified the following predictors for specific effects of occupational pressures:

- Problem focus is a significant positive predictor for organisational commitment $(\beta=, 558, \mathrm{p}<.001)$ : table 2 ;

- Drive $A$ is a significant positive predictor for state of mind $(\beta=, 384$, $\mathrm{p}<.02$ ): table 3 ;

- Control is a significant positive predictor for resilience $(\beta=, 510$, $\mathrm{p}<.002$ ): table 4;

The regression model comprised of 3 combined factors (drive, impatience and life/work balance) predicts significantly the level of experiencing physical symptoms/ physical well-being (Table 5).

Table 2 Problem focus as predictor for Organisational Commitment

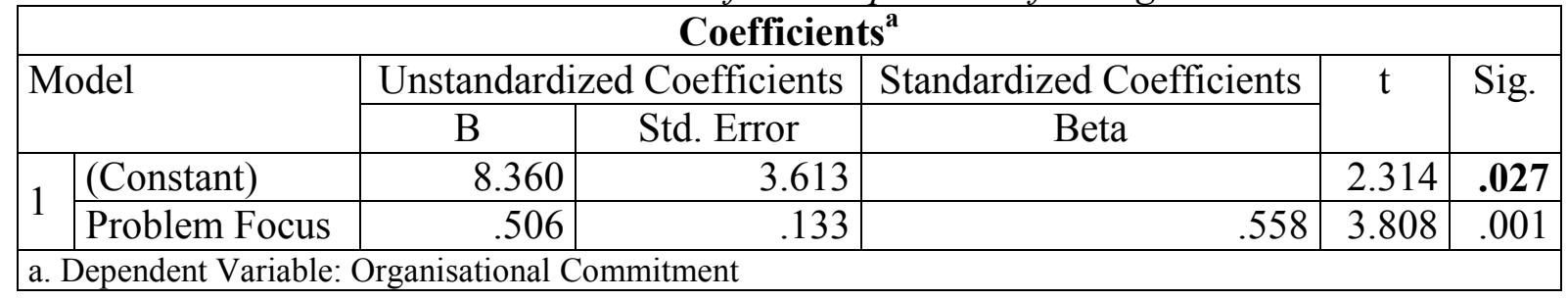


Table 3 Drive A as predictor for State of mind

\begin{tabular}{|c|c|c|c|c|c|c|}
\hline \multicolumn{7}{|c|}{ Coefficients $^{\mathrm{a}}$} \\
\hline \multirow{2}{*}{\multicolumn{2}{|c|}{ Model }} & \multicolumn{2}{|c|}{ Unstandardized Coefficients } & \multirow{2}{*}{$\frac{\text { Standardized Coefficients }}{\text { Beta }}$} & \multirow[t]{2}{*}{$\mathrm{t}$} & \multirow[t]{2}{*}{ Sig. } \\
\hline & & $\mathrm{B}$ & Std. Error & & & \\
\hline \multirow{2}{*}{1} & (Constant) & 5.771 & 5.926 & & .974 & .337 \\
\hline & Drive & .964 & .410 & .384 & 2.350 & .025 \\
\hline
\end{tabular}

Table 4 Control as predictor for Resilience

\begin{tabular}{|c|c|c|c|c|c|c|}
\hline \multicolumn{7}{|c|}{ Coefficients $^{\mathrm{a}}$} \\
\hline \multirow{2}{*}{\multicolumn{2}{|c|}{ Model }} & \multicolumn{2}{|c|}{ Unstandardized Coefficients } & \multirow{2}{*}{$\begin{array}{c}\text { Standardized Coefficients } \\
\text { Beta } \\
\end{array}$} & \multirow[t]{2}{*}{$\mathrm{t}$} & \multirow[t]{2}{*}{ Sig. } \\
\hline & & $\mathrm{B}$ & Std. Error & & & \\
\hline \multirow{2}{*}{1} & (Constant) & 10.093 & 2.397 & & 4.211 & .000 \\
\hline & Control & .493 & .147 & .510 & 3.352 & .002 \\
\hline
\end{tabular}

Table 5 Drive A, Impatience and life/ work balance as predictors for Physical symptoms/ physical well-being

\begin{tabular}{|c|c|c|c|c|c|c|}
\hline & & & Coefficients $^{2}$ & & & \\
\hline & odel & $\begin{array}{r}\text { Unstar } \\
\text { Coef }\end{array}$ & $\begin{array}{l}\text { ardized } \\
\text { cients }\end{array}$ & $\begin{array}{l}\text { Standardized } \\
\text { Coefficients }\end{array}$ & $\mathrm{t}$ & Sig. \\
\hline & & $\mathrm{B}$ & Std. Error & Beta & & \\
\hline & (Constant) & 29.152 & 5.448 & & 5.351 & .000 \\
\hline 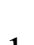 & Drive & .600 & .179 & 420 & 3.350 & .002 \\
\hline 1 & Patience/Impatience & -.445 & .157 & -.355 & -2.840 & .008 \\
\hline & Life/ Work Balance & -.832 & .219 & -.477 & -3.802 & .001 \\
\hline
\end{tabular}

Summarising, specific individual differences on personality and coping strategies are significantly influencing how the ICU medical staff manages to cope with occupational stress and various sources of pressure.

\section{Conclusions and discussions}

The results have identified a specific multidimensional profile of occupational stress for the romanian participants of the ICU medical staff, significant correlations between variables (for example sources of pressure, coping strategies, personality factors, satisfaction and self-evaluation of performance) and specific predictors for the measurable perceived effects of occupational pressures.

These findings support, for example, those of a study [1] about the perception of resilience and indicators of occupational stress, and those of another study [5] about the quality of predictors of resilience and the attachment to the organization for loneliness at work (LW).

\section{Implications of the study and intervention / management strategies}

The results of this study could provide useful diagnostic, correlational and predictive information about measurable indicators of the perception of occupational pressures, personality factors, coping strategies and specific effects of stress on individual and group/ department level of the ICU medical staff. Based on these results, similar findings $[1,4,5,6]$ and the experience of intervention in other occupational settings, we suggest the following strategies for improving organisational decisions and for the development of intervention in stress/ 
pressure management for an ICU medical staff at personal and organizational level:

- stimulating and training social skills, communication and empathic abilities, resilience, trust, emotional intelligence and active coping strategies;

- training relaxation techniques;

- developing more opportunities for social interaction of staff members;

- addressing maladaptive cognitions on control and resilience;

- training technical competence and procedures;
- improving organizational culture, job analysis strategies and work environment.

Further research should focus on better understanding of coping strategies used by highly resilient medical staff and how they maintain a more resilient and healthier psychological profile. Also, an exploration of emotional distress in relation to communication skills, ethical problems, psychological abilities and mindfulness among ICU professionals (longitudinal study) could provide resources for the development of further preventive strategies.

\section{References}

[1] Brate A.T., The perception of resilience and indicators of occupational stress. In: Serban Ionescu (Ed.), Mihaela Tomita \& Sorin Cace (Associate Editors), Proceedings of The $2^{\text {nd }}$ World Congress on Resilience: From Person to Society, pp. 1305-1310, Timisoara, Romania, 8-10 May, 2014

[2] Brate A.T., Spre un model comprehensiv-integrativ de diagnoză şi management al stresului organizaţional. În: E. Avram \& C.L. Cooper, Psihologie organizaţionalmanagerială. Tendinţe actuale, Iași, Polirom, 2008, pp. 578-591

[3] Brate A., Diagnoza multidimensională a stresului ocupaţional la manageri. Psihologia Resurselor Umane, Vol. II, Nr. 2, pp. 42-52, 2004

[4] Mealer M. et al., The presence of resilience is associated with a healthier psychological profile in intensive care unit (ICU) nurses: Results of a national survey. International Journal of Nursing Studies, Volume 49, Issue 3, pp. 292-299, 2012

[5] Stoica M. \& Brate A.T., Relațiile dintre reziliență, atașamentul față de organizație, sprijinul superiorilor și singurătatea la locul de muncă într-o unitate medicală, Psihologia Resurselor Umane, Vol. XI, Nr. 2, pp.71-82, 2013

[6] VanMol M.M.C., Kompanje E.J.O., Benoit D.D., Bakker J., Nijkamp M.D., The Prevalence of Compassion Fatigue and Burnout among Healthcare Professionals in Intensive Care Units: A Systematic Review. PLOS ONE 10(8): e0136955. doi: 10.1371/journal.pone.0136955, 2015

[7] Williams S. \& Cooper C.L., Measuring Occupational Stress: Development of the Pressure Management Indicator. Journal of Occupational Health Psychology, Vol. 3, No. 4, pp. 306-321, 1998 